\section{Tratado de tiroides}

\author{
Alfredo Jácome Roca, MD, FACP.
}

Internista-Endocrinólogo. Miembro de Número, Academia Nacional de Medicina; Miembro Honorario, Asociación Colombiana de Endocrinología, Diabetes y Metabolismo.

Tratado de tiroides. Editor: Carlos Alfonso Builes Barrera. Prólogo: Luz Ángela Casas Figueroa. Primera Edición, 2014. ISBN: 978-958-99814-6-7.

Editado por Producciones Científicas Ltda. Revisor Médico: Carlos Eduardo Rodríguez. Entidad Editora: Asociación Colombiana de Endocrinología, Diabetes y Metabolismo. Impresor: Pro-Offset Editorial S.A., Bogotá, Colombia

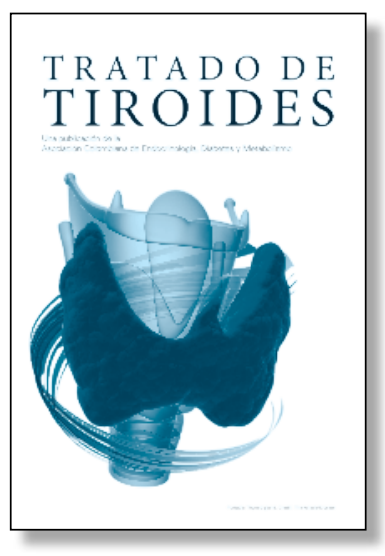

E comienzo de 2015 nos trajo una agradable sorpresa editorial. Apareció un libro - finamente impreso por la Asociación Colombiana de Endocrinología, Diabetes y Metabolismo- titulado Tratado de Tiroides, cuyo editor es un acucioso tiroidólogo, el doctor Carlos Alfonso Builes Barrera. Recordé lo difícil que fue, hace más de 40 años, haber pasado por el mismo trabajo editorial cuando con la Sociedad (ahora Asociación) de Endocrinología, publicamos $L a$ Tiroidología en Colombia, con muchas menos pretensiones que esta documentada obra.

En el primer número de nuestra revista, tuve oportunidad de publicar "Aportes colombianos a la Endocrinología", artículo donde se observa cómo han cambiado las cosas, pienso que para bien. Las mejores investigaciones colombianas sobre tiroides las dirigen cirujanos de cáncer de cuello e inmunólogos interesados en la autoinmunidad, con experiencia en investigación. Controlado está ya el bocio endémico, así existan pocas zonas yodo-deficientes en nuestro país; desapareció por tanto el cretinismo, y el hipotiroidismo congénito se detecta en el recién nacido, con cobertura casi total. En cambio, la enfermedad tiroidea autoinmune es común (tanto la enfermedad de Graves como la tiroiditis de Hashimoto), al igual que el hipotiroidismo subclínico, en particular en las mujeres posmenopáusicas; el bocio/nódulo tiroideo sigue siendo objeto de estudio por su potencial de malignidad. De vez en cuando, hay epidemias virales seguidas de episodios de tiroiditis subaguda, la discusión sigue sobre si las cirugías para cáncer papilar de tiroides (el más común y de buen pronóstico), deben ser conservadoras o radicales. Entre las pruebas de función tiroidea, el metabolismo basal, la yodoproteinemia y la captación de yodo radiactivo, desaparecieron por completo al ser remplazadas por la TSH ultrasensible, la tiroxina libre y los anticuerpos antitiroideos.

Los 59 colaboradores del libro escriben 55 capítulos en 410 páginas; allí se discuten desde el tiroides normal hasta las patologías benignas y malignas comunes y raras, disfunciones del tipo hiper e hipo -tan características de la endocrinología clásica- pasando por la valoración de la glándula con pruebas funcionales modernas y exactas dentro de lo que cabe en un organismo complejo. Se incluyen además tópicos especiales como la glándula normal y patológica en la infancia, embarazo y ancianidad, la patología autoinmune, la genética y la epigenética, y los enfoques médicos, quirúrgicos y de medicina nuclear en el manejo de las diferentes enfermedades.

El Tratado de Tiroides es un libro dirigido particularmente a endocrinólogos clínicos y a médicos con especialidades primarias, en las que la patología tiroidea se ve con frecuencia. Es invaluable para residentes, mientras que para estudiantes y otros profesionales de la salud luce más como una obra de consulta.

El estilo de incluir un caso clínico al comienzo de capítulo (vignet$t e$ ), que es analizado después, al finalizar su lectura, es una forma muy de moda en los textos americanos, para aterrizar un poco la teoría en casos prácticos. Y todo el personal de profesionales de salud debe atender a estos enfermos con sabiduría, habilidad y paciencia, ya que "en nuestro país, más del $2 \%$ de las mujeres adultas tienen hipotiroidismo y entre 13 y $67 \%$ tienen nódulos tiroideos por ecografía", citando a la presidenta de la ACE, Luz Ángela Casas, quien escribe el prólogo.

Las ilustraciones y tablas son profusas y explicativas, las referencias son actualizadas. Aunque hay autores que citan algunos estudios colombianos o realizados en la región, esta no fue la norma; otras veces dichas investigaciones y revisiones eran autocitas, técnica válida de la cual no debe abusarse.

Autores entre los de mi época - segunda generación de endocrinólogos- escriben pocos, los doctores Orrego, Ahumada y Sánchez Escobar. Ya pocos de los nuevos especialistas son entrenados en el exterior pero sí muchos han sido entrenados en Colombia, egresados de los muy buenos 6 o 7 centros universitarios aprobados para estos menesteres, concentrados en Bogotá y Medellín. La afiliación universitaria de los endocrinólogos se ve menos clara que antaño, ya que la mayoría laboran para instituciones prestadoras de salud, donde la labor asistencial es tan pesada que no se presta para la docencia, aun en los casos de los hospitales universitarios. Para los clínicos se ve más la conexión de docente/hora de cátedra. Aunque la hora no se ve en el reloj en los tiempos actuales, sino en el celular o la tableta, igual los médicos son esclavos del tiempo y de las dificultades de movilidad. Diremos que ya los tiempos del profesor de tiempo completo son cosa del pasado. Aunque el trabajo cotidiano no permite otros espacios, debemos aplaudir la inquietud intelectual y generosidad de los autores, que sabemos le están quitando tiempo a sus familias y sacrificando horas de sueño.

Textos sobre tiroides para pacientes hay varios, incluyendo uno del Dr. Builes, editor del Tratado de Tiroides. Pero textos para médicos que traten exclusivamente el tema de esta glándula, son pocos. En nuestra región existe el Tratado Argentino de Tiroides, escrita por especialistas del cono sur. Los más conocidos provienen de Norteamérica. Por ejemplo, el de Werner e Ingbar, cuya $9^{a}$ edición (2004) ya está a cargo de Utiger y Bravermann. Leslie de Groot tradicionalmente escribió por años un texto de tiroides muy documentado (The thyroid and its diseases) que vino a remplazar anteriores obras de James Howard Means, de Retetoff y Stanbury, pero que ahora cambió por su muy actualizado portal sobre la tiroides, (www.thyroidmanager. org), que sorprende por lo extenso y completo de los temas tratados, por estar muy bien documentado y por tener sus capítulos escritos por los mejores tiroidólogos del mundo, pudiéndose aún así ver de manera gratuita.

Bienvenida pues esta nueva y documentada obra - no sólo a nuestros anaqueles - sino a su juiciosa lectura. Ojalá remedie aunque sea en parte el desconocimiento sobre el tema que no es raro en los médicos generales e incluso en algunos especialistas, que se animen a comprenderlo y a utilizar el conocimiento adquirido en los numerosos pacientes con enfermedades de esta glándula. 